\title{
Comparison of GRACE with in situ hydrological measurement data shows storage depletion in Hai River basin, Northern China
}

\author{
Juana Paul Moiwo1, Yonghui Yang ${ }^{1 *}$, Huilong Li', Shumin Han', Yukun Hü,2 \\ ${ }^{1}$ Key Laboratory for Agricultural Water Resources, Agricultural Resources Research Centre, Institute of Genetics \\ and Developmental Biology, Chinese Academy of Sciences, 286 Huaizhong Road, Shijiazhuang 050021, China \\ ${ }^{2}$ Hebei Provincial Academy of Water Resources, 310 Taihua Road, Shijiazhuang 050051, China
}

\begin{abstract}
Water storage change has implications not only for the hydrological cycle, but also for sustainable water resource management in especially semi-arid river basins. Satellite/remote sensing techniques have gained increasing application in monitoring basin and regional hydrological processes in recent decades. In this study, the latest version of GRACE (Gravity Recovery and Climate Experiment) is used to estimate total water storage change in the Hai River basin (HRB) of Northern China for the period January 2003 to December 2006. Time-series comparisons show a good agreement between the estimated storage change from the GRACE satellite data and in situ hydrological measurement data at especially the seasonal cycle with $\mathrm{R}=0.82$ and $\mathrm{RMSE}=17.25 \mathrm{~mm}$. The good agreement suggests that GRACE detects storage change in the $318866 \mathrm{~km}^{2} \mathrm{HRB}$ study area. It also implies that the in situ hydrological measurements of soil moisture and groundwater sufficiently characterise storage change in the semi-arid river basin. Change in soil moisture storage is less than that in saturated storage, suggesting that storage depletion in the basin is mainly in the saturated zone. Both the GRACE and hydrological measurement data indicate storage loss in the range of 12.72 to $23.76 \mathrm{~mm} / \mathrm{yr}$ - a phenomenon that has been detected in previous studies in the basin. GRACE hydrology data could therefore be handy in monitoring storage dynamics and water availability in the study area. As GRACE data are available for virtually every region of the world, their application in conjunction with hydrological models could improve hydrological studies. This may lead not only to water balance closures, but also to sustainable water resource management at basin to regional scale.
\end{abstract}

Keywords: Hai River basin, GRACE, saturated storage, soil moisture storage, hydrological measurement data, total water storage change

\section{Introduction}

Water shortage on North China Plain (NCP), the largest wheat/ maize production zone in China, is a limiting factor to socioeconomic development in the region (Guobin et al., 2004; Yang et al., 2006). Per-capita water availability on the plain is amongst the lowest globally (Nakayama et al., 2006). Since the founding of the People's Republic of China in 1949, flow has dropped to insignificant levels in almost all the rivers on the plain due largely to repeated dam construction for hydroelectric power generation, and urban/industrial water supply (Brown et al., 2005). Hence agriculture, the main stay of the larger rural population, relies heavily on groundwater irrigation to ensure sufficient food production for the staggering population. Agricultural irrigation has induced severe groundwater drawdown in the region, which is occurring at an estimated rate of 1.5 to $2.0 \mathrm{~m} / \mathrm{yr}$. It is feared that water shortage on the plain would develop into a major social crisis if sustainable countermeasures are not implemented in time (Fei, 1998; Brown et al., 2005; Yang et al., 2006; Blanke et al., 2007).

Before the satellite age, monitoring of storage availability and exploitation relied largely on piezometric data and ad hoc

\footnotetext{
* To whom all correspondence should be addressed.

前 +86-311-85814368; fax: +86-311-85815093; e-mail: yonghui.yang@ms.sjziam.ac.cn

Received 15 May 2009; accepted in revised form 14 September 2009.
}

model simulations. Such measures were often limited by elaborate input requirements and parameterisation, data inconsistency and complicated data formatting, spatial and temporal data gaps, and instrumental and human oversights (Rodell et al., 2007). In recent decades, however, more direct and efficient methods have been developed to monitor storage dynamics and availability in especially (semi)-arid river basins. One such method is GRACE (Gravity Recovery and Climate Experiment).

GRACE has been proven reliable, and it offers a great potential for water storage closure on basin to regional scale (Swenson et al., 2006; Yeh et al., 2006). GRACE data are available for virtually all river basins and can be inverted for water storage change in the thin layer of the earth (Brunner et al., 2006; Swenson et al., 2006) with unprecedented accuracy (Tapley et al., 2005; Flamsteed, 2007). GRACE is promising because no global network exists of hydrological observations with temporal and spatial resolutions necessary to characterise storage on regional to continental scale (Swenson et al., 2006; Klees et al., 2006; Chen et al., 2007).

GRACE mission was jointly launched by NASA (National Aeronautics and Space Administration) and DLR (Zentrum für Luft-und Raumfahrt) in March 2002. The mission was due to expire in April 2007, but has been approved to continue through early 2010 (Rodell et al., 2007). GRACE consists of 2 satellites (trailing each other at a distance of $\approx 220 \mathrm{~km}$ ) in identical earth orbits. The satellite-to-satellite separation distance is monitored by highly sensitive onboard microwaves as they move over gravity highs and lows (at an initial altitude of $485 \mathrm{~km}$ ). 
Gravity fields are generally influenced by non-gravitational forces, glacier isostatic adjustments, mass transports in the atmosphere and oceans, and redistribution of water, snow and ice on the land surface. Hence after corrections for the nongravitational forces, GRACE gravity field solutions reflect water storage change on the earth's surface. This includes storage change in groundwater, soil moisture, and in surface water bodies like rivers, lakes and snow/ice packs (Klees et al., 2006). GRACE data, after de-striping for the so-called northsouth trending errors, can be applied at a spatial resolution of $\approx 200000 \mathrm{~km}^{2}$ (Yeh et al., 2006). A spatial resolution of this magnitude is commensurate with most river basins for which in situ hydrological measurements are available (Swenson et al., 2006).

Previous studies have shown that groundwater and rootzone soil moisture storage do not only exhibit significant variability, but also adequately reflect total storage change in river basins at monthly to seasonal scale (e.g. Eltahir and Yeh, 1999; Seneviratne et al., 2004; Syed et al., 2005; Garcia et al., 2006; Hinderer et al., 2006; Swenson et al., 2006; Rodell et al., 2007; Rietbroek, 2007). In this paper therefore, GRACE and the combined hydrological measurement data of soil moisture and groundwater were used to analyze total water storage change in the $318866 \mathrm{~km}^{2}$ Hai River basin (HRB). We spatially averaged and compared the GRACE data with the hydrological measurement data and showed that GRACE detects storage loss in the semi-arid HRB study area.

\section{Data and method}

\section{Location and hydrology of the study area}

Hai River basin is one of the most important grain-production regions in Northern China. Lying between 35.01 and $42.72{ }^{\circ} \mathrm{N}$ and 111.95 and $119.84^{\circ} \mathrm{E}$ (Fig. 1), it has an area of $\approx 318866$ $\mathrm{km}^{2}$ and a population of $112 \mathrm{~m}$. (Wu et al., 2008). In the basin, land surface elevation is higher than $2832 \mathrm{~m}$ in the Taihang Mountains and below $5 \mathrm{~m}$ in the littorals of the Sea of Bohai. As nearly all the rivers in the basin are repeatedly dammed, river flow is severely limited. The climate is typically semi-arid with cold winters and hot summers. In the basin, precipitation is uneven both in space and time and with an annual average of $\approx 550 \mathrm{~mm} / \mathrm{yr}$. Over $70 \%$ of the precipitation falls in the summer months of June, July and August (Yang et al., 2006). Designations like commercial, industrial, residential and urban land-use form a small, but vital part of the landscape. However, agriculture is the largest land-use type accounting for over $90 \%$ of the arable lands. Over $69 \%$ of the cultivated lands are under a continuous wheat-maize rotation cropping system (Yang et al., 2002; Yang and Tian, 2009).

In the study area, groundwater is predominantly a bicarbonate type (Fei, 1998). Hydrogeologically, quaternary-aged aquifers of inter-fingering gravel, sand and silt deposits extend to a depth of $400 \mathrm{~m}$ below surface alluvial fans (Zhu et al., 1995; Chen et al., 2007). While the potential for groundwater storage is highest in the plains, significant recharge largely occurs in the gravelly piedmont regions (Yang et al., 2002; Nakayama et al., 2006). Land productivity has been enhanced since the early 1950s due to extensive water conservancies, afforestation, soil improvement measures and farmland development. To further facilitate agricultural production, thousands of tube-wells and pumping stations have been developed. While this has enhanced land productivity, it has at the same time led to drastic groundwater drawdown and the development of widespread

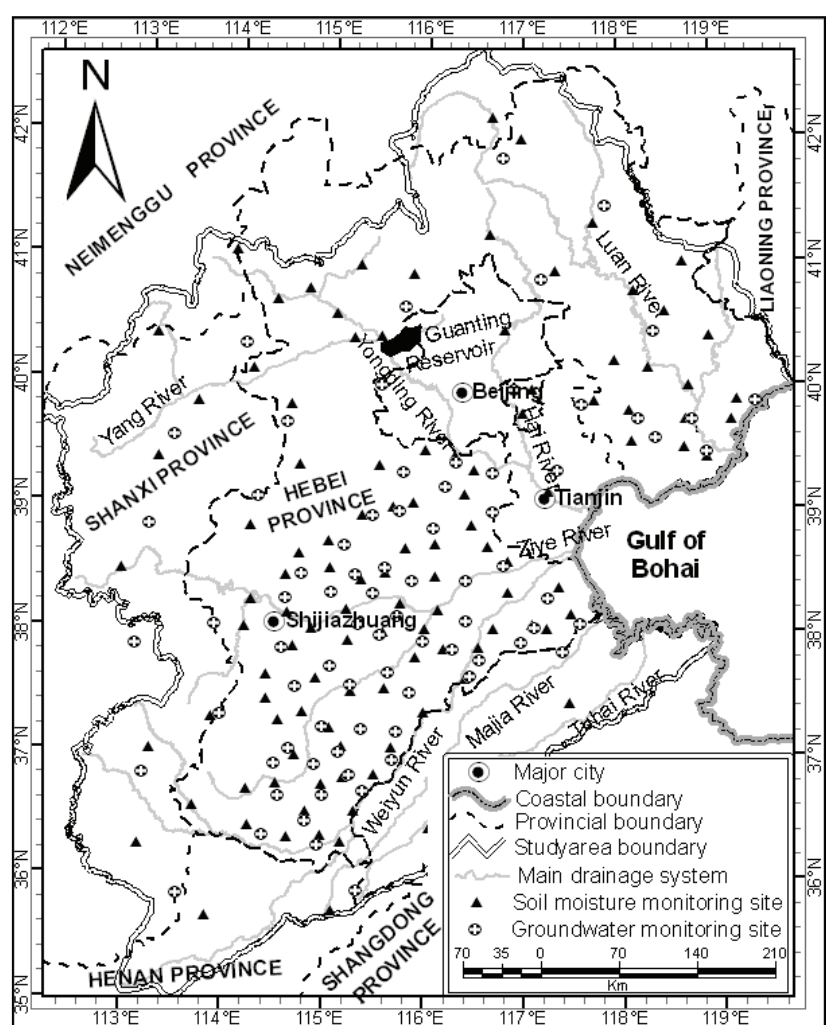

Figure 1

Location map of the study area showing main river systems and cities; soil moisture and water table monitoring sites; and provincial and coastal boundaries

groundwater depression cones in the basin (Brown et al., 2005; $\mathrm{Xu}$ and Cai, 2005; Yang et al., 2006).

\section{GRACE data acquisition and processing}

GRACE data release-04 (RL04) spanning from January 2003 to December 2006 was used in the study. This set of data constitutes a significant improvement over earlier releases because of improvements in the background processing models (Chambers, 2007; Kusche et al., 2008). The GRACE data used in this study were obtained from http://geoid.colorado. edu/grace/grace.php - developed by Sean Swenson under the auspices of NASA Research, Education and Applications Solution Network (NASA-REASON). The site provides online interfaces for a series of GRACE data analysis. GRACE gravity data, when filtered or de-stripped for the so-called correlated north-south trending errors can be applied at a spatial resolution of $\approx 200000 \mathrm{~km}^{2}$, which is commensurate with the $\approx 318866 \mathrm{~km}^{2}$ study area. De-stripped GRACE data are widely used in the estimation of terrestrial water storage change (e.g. Swenson et al., 2006; Rodell et al., 2007; Slobbe et al., 2009).

In this study, GRACE monthly water storage anomalies were computed at a Gaussian half-width of $200 \mathrm{~km}$. This smoothing radius sufficiently constrained the data on the 318 $866 \mathrm{~km}^{2}$ study area. To minimise the effect of geographical truncation on the analysis, a maximum of $1^{\circ}$ was maintained around the basin (see also Mayer-Guerr et al., 2007). The monthly storage anomalies (which are regularly spaced $1^{\circ} \mathrm{x}$ $1^{\circ}$ point data) were projected to WGS 1984 UTM Zone 51N coordinate system. The projected data were then interpolated at a grid-cell size of $1000 \mathrm{~m} \times 1000 \mathrm{~m}$ via the IDW (inverse 
distance weighted) interpolation method on GIS platform. The basin-averaged monthly storage anomaly was afterwards derived from the raster maps after re-truncation to the study area. This processing technique was necessary because the spatial extent of HRB defined in our study (see Fig. 1) is essentially different from that on the GRACE website - where the basin definitions are based on TRIP (Total Runoff Integrating Pathways; see Oki and Sud (1998)). Furthermore, this technique supports sufficient spatial display of the water storage components.

Uncertainty and bias estimates of GRACE data are beyond the scope of this paper. However, this aspect of the data is well reported in several other studies, especially those concerning GRACE hydrological applications (e.g., Klees et al., 2006; also visit http://grace.jpl.nasa.gov/publications/ for related studies). Furthermore, the increasing and wide application of GRACE data in hydrological studies is, in itself, a good manifestation of the degree of accuracy and reliability associated with this source of data.

\section{Hydrological measurement data acquisition and processing}

The hydrological measurement data used in this study basically comprise of in situ soil moisture and groundwater measurement data. Data from a total of 129 soil moisture and 87 water table measurement stations (see Fig. 1) were collected for January 2003 to December 2006.

The water table data were obtained from the Hydrological and Water Resources Bureau of Hebei Province, and consisted of 2 water-table measurements per month (the $6^{\text {th }}$ and $26^{\text {th }}$ of each month). Only monitoring wells in the unconfined aquifer and with reasonable distance from production wells were considered for the groundwater measurement data. Additional hydrogeological data including specific yield were obtained from Geological Memoirs (1992). Because the confined and phreatic aquifer systems are hydraulically interconnected via outcrops, the data were considered representative of saturated storage in the basin.

The soil moisture data, on the other hand, were obtained from the Meteorological Bureau of Hebei Province. The bureau maintains measurements of soil moisture at every $10 \mathrm{~cm}$ depth for the first $50 \mathrm{~cm}$ soil depth. The data consist of gravimetric soil moisture measurements taken on the $8^{\text {th }}, 18^{\text {th }}$ and $28^{\text {th }}$ of each month. The data were converted into equivalent soil moisture via the bulk density factor.

Because the hydrological measurement data are spatially not evenly distributed, they were analyzed for temporal stability. The concept of temporal stability was introduced by Vachaud et al. (1985) and defines the time-invariant association between spatial locations and classical statistical parametric values of given properties. Temporal stability analysis reduces the number of measurements needed to establish the general behaviour of a data set by identifying those locations that are representative of a given area with regard to that data property (Martínez-Fernández and Ceballos, 2003). The relative difference parametric test (Vachaud et al., 1985) was used to determine temporal consistency among the measurement sites. In relative difference parametric tests, time-stable locations are those locations with minimal deviation from the mean relative difference (Martínez-Fernández and Ceballos, 2003). For the purpose of this study, all measurement sites with standard mean relative difference deviation above the average mean $(5.20 \mathrm{~mm}$ for the soil moisture and $5.07 \mathrm{~m}$ for the water table

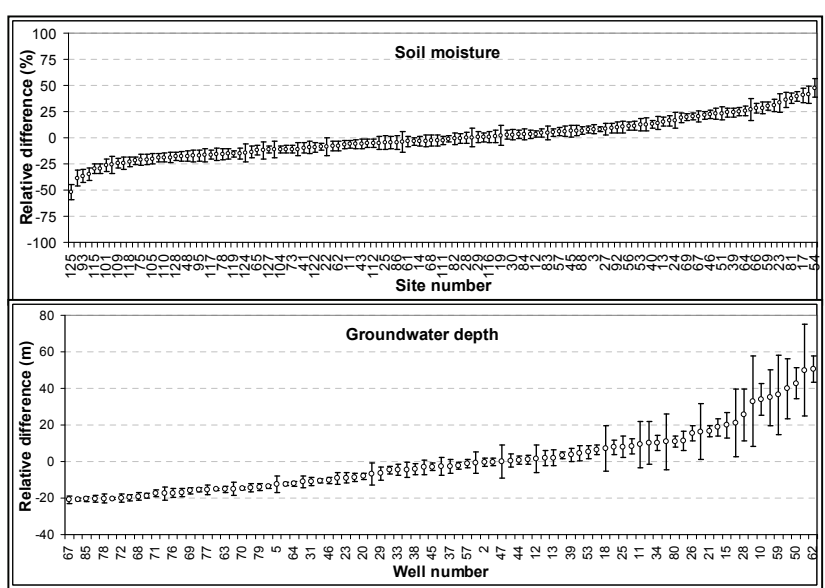

Figure 2

Relative difference averaged for soil moisture (top plate) and groundwater (bottom plate) measurement data; error bars denote standard deviation of mean relative difference (note that not all the station numbers are depicted on the $x$-axis because of the large number of observation sites)

data) were considered outliers and were therefore rejected. Based on the analysis and the selection criteria, data from 77 stations (out of 129 soil- moisture measurement stations) and 65 wells (out of 87 water-table monitoring wells) were eventually used. The results of the temporal stability analysis are plotted in Fig. 2.

The statistically tested data (for both the soil moisture and groundwater) were then projected on the same coordinate system as that for the GRACE data and interpolated in more or less the same way at a grid-cell size of $1000 \mathrm{~m} \times 1000 \mathrm{~m}$. As most of the basin is under wheat/maize (shallow-rooted crops with root penetration hardly exceeding $50 \mathrm{~cm}$ ) rotational cultivation system, soil moisture storage in the 50 to $200 \mathrm{~cm}$ soil depth should be fairly stable (Han et al., 2008). Hence storage change in the top $50 \mathrm{~cm}$ soil depth was assumed to be representative of unsaturated storage change in the study area (Yang et al., 2006). To also convert change in water-table depth into saturated storage change, the well data were multiplied by the basin-averaged specific yield - taken as 0.066 (see Geological Memoirs, 1992).

\section{Auxiliary data}

Auxiliary data in this study refer to the set of data not directly factored into the water balance model, but are used to explain the behaviour of water storage change in the basin study area. The set of auxiliary data used for the above purpose includes precipitation, evapotranspiration, irrigation and temperature data. The temperature and precipitation data were collected from 67 meteorological stations that are relatively evenly distributed over the study area - see Wu et al. (2008) for the location of the meteorological stations in the HRB study area. The stations are owned and operated by China National Meteorological Bureau (CNMB) and are equipped with automatic data-loggers. Those of irrigation and evapotranspiration were collected at the Luancheng Comprehensive Agricultural Eco-systems Experimental Station (LCAEES). The station is owned and run by the Chinese Academy of Sciences (CAS). LCAEES (located at latitude $37^{\circ} 53^{\prime} \mathrm{N}$ and longitude $114^{\circ} 41$ E) maintains a large weighing lysimeter for measuring evapotranspiration on well-irrigated maize/wheat fields. Over 69\% 
of the basin is under irrigated wheat/maize rotation farming (Yang et al., 2002; Yang and Tian, 2009) hence the lysimeter data should be representative of the study area.

\section{Hai River basin water balance model}

In Hai River basin, over $80 \%$ of the plains are under wheat and maize crops (both of which are shallow-rooted and heavily irrigated crops). In the plains therefore, significant soil moisture variation is limited mainly to the first $50 \mathrm{~cm}$ root-zone (Yang et al., 2006). Storage in the intermediate zone (which is unusually thick due to drastic groundwater drawdown) is relatively stable (Han et al., 2008). Furthermore, surface water is highly limited in the basin due to repeated damming for hydroelectric power generation, and urban and industrial water supply (Yang and Tian, 2009). Hence the most important sources of storage change in the basin are soil moisture and groundwater. In the terrestrial-based water balance approach, these sources of storage change are equated to GRACE total water storage change (Swenson et al., 2006; Yeh et al., 2006; Rodell et al., 2006) as:

$$
T W S C=S M S C+G W S C
$$

where:

TWSC is total water storage change

$S M S C$ is storage change in soil moisture

GWSC is storage change in groundwater

The term on the left-hand side of Eq. (1) was derived from GRACE data whereas those on the right-hand side were computed from in situ hydrological measurements of soil moisture and groundwater. The terms on the opposite sides of the equation should be commensurate and therefore comparable.

\section{Results and discussion}

\section{Groundwater depth and total water storage anomaly}

Figure 3 (top plate) depicts the dynamics of the basin-averaged monthly and seasonal groundwater depth anomaly plotted from the monitoring well data. Also depicted on Fig. 3 (bottom plate) is the basin-averaged monthly and seasonal total water storage anomaly plotted from GRACE data. The time-series plots do not only have striking similarities in especially the seasonal phases, but also indicate storage loss in the basin. Storage loss is readily noticeable from the slopes of the linear trend lines. The slopes further suggest that the magnitude of change in groundwater depth is higher than that in the GRACE-derived total water storage anomaly. The trend of change in especially the groundwater depth data suggests that storage change in the basin is predominantly in saturated storage.

As shown in the next sections, storage change obtained from the combined groundwater and soil moisture storage is commensurate with the GRACE-derived total water storage change. It then implies that saturated storage loss in the basin is somewhat counter-balanced by storage gain in especially root-zone soil moisture. This is because agricultural irrigation, which is almost exclusively dependent on groundwater pumping, augments root-zone soil moisture storage in the wheatmaize rotational cultivation system (also see Tong et al., 2009).

The seasonal curves in Fig. 3 show storage loss in spring (March to May) and storage gain in autumn (September to November). Wheat irrigation is the main cause of saturated storage loss in spring (Yang et al., 2006). Autumn is usually

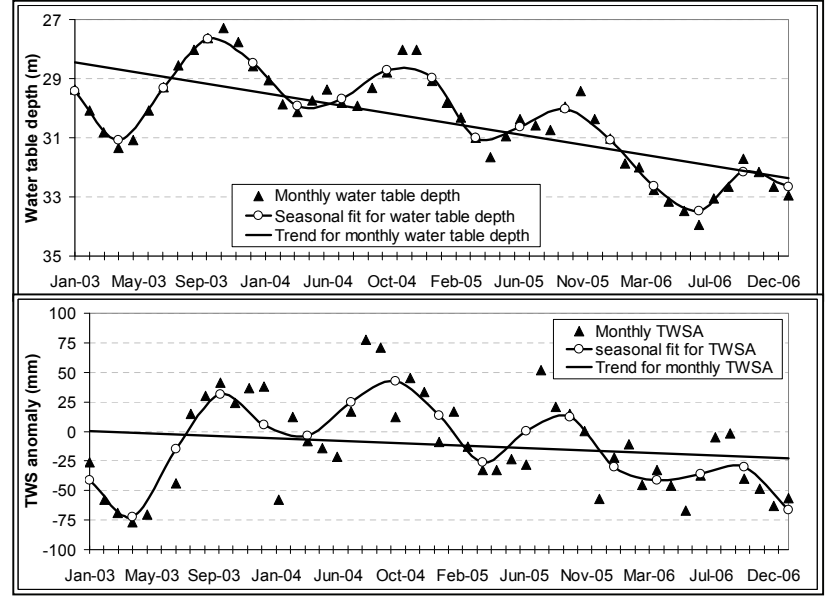

Figure 3

Time-series of the basin-averaged monthly and seasonal water table depth anomaly plotted from monitoring well data (top plate), and of GRACE total water storage anomaly (bottom plate) for the period 2003-2006

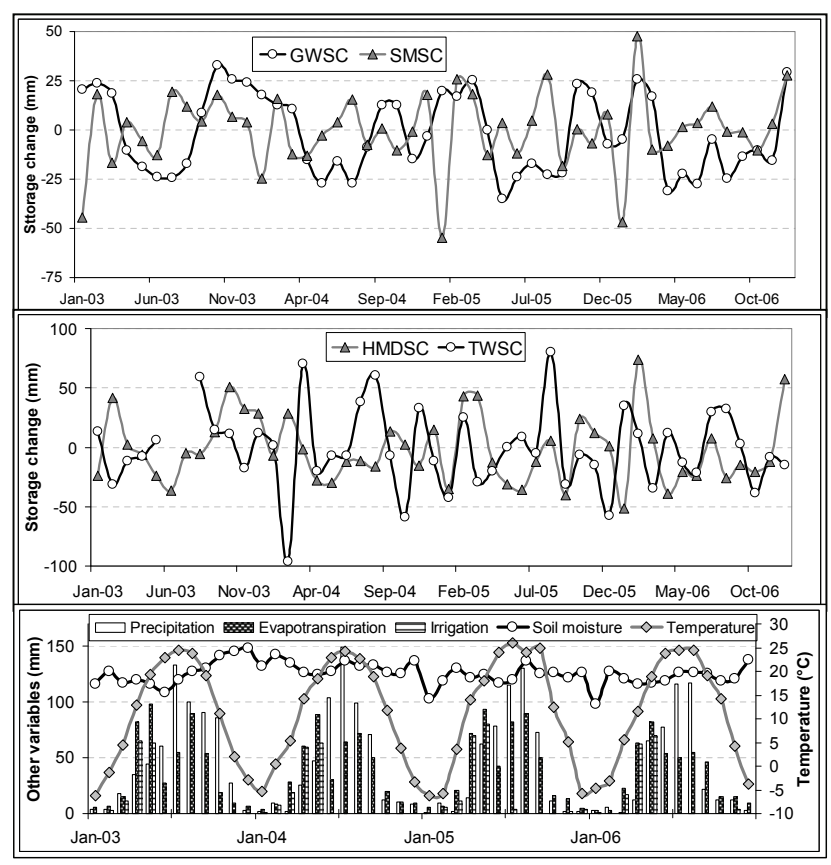

Figure 4

Time-series comparisons of the basin-averaged monthly storage change in soil moisture with groundwater (top plate); and in hydrological measurement (soil moisture and groundwater combined) with GRACE data (middle plate); along

with monthly trends of precipitation, irrigation, temperature, evapotranspiration and soil moisture (bottom plate) for the period 2003-2006. Acronyms are as defined in Table 1.

the harvest season, and a relatively high rainfall in the preceding summer (June to August) augments storage in the autumn season (see also Nakayama et al., 2006; Han et al., 2008).

\section{Monthly storage change}

Figure 4 (top plate) is a time-series of monthly storage change in soil moisture and in groundwater in the study area. In the middle plate of Fig. 4 is a comparison of the GRACE-derived total water storage change with storage change computed from 


\begin{tabular}{|c|c|c|c|c|c|c|c|c|c|}
\hline \multicolumn{10}{|c|}{$\begin{array}{l}\text { TABLE } 1 \\
\text { Details on the statistical analysis for the storage components of } \\
\text { precipitation, soil moisture, groundwater, and total water storage }\end{array}$} \\
\hline Variable $(\mathrm{mm})$ & Min & Max & Mean & STD & $\mathbf{R}$ & $\mathbf{R}^{2}$ & SEM & SEE & RMSE \\
\hline \multicolumn{10}{|c|}{ MONTHLY } \\
\hline SMSC & $\mid-54.80$ & 47.75 & 0.86 & 18.96 & - & - & - & - & - \\
\hline GWSC & $\mid-35.02$ & 33.02 & -1.98 & 0.06 & - & - & - & - & - \\
\hline HMDSC & -47.87 & 64.85 & -1.12 & 28.36 & - & - & - & - & - \\
\hline TWSC & -96.03 & 80.35 & -1.06 & 33.99 & - & - & - & - & - \\
\hline GWSC & - & - & - & 36.19 & 0.08 & 0.01 & 5.17 & 31.82 & 35.84 \\
\hline TW: & - & - & - & 36.88 & 15 & 2 & 38 & 33.68 & 36.49 \\
\hline TW & - & - & - & 28.04 & 0 & 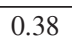 & 4.09 & 26.91 & 27.81 \\
\hline TWSC v & - & - & - & $\overline{33.69}$ & $\overline{0.56}$ & 0.31 & $\overline{4.91}$ & $\overline{28.23}$ & $\overline{33.47}$ \\
\hline \multicolumn{10}{|c|}{ SEASONAL } \\
\hline SMSC & \begin{tabular}{|l|}
-19.76 \\
\end{tabular} & 32.60 & 2.47 & 14.45 & - & - & - & - & - \\
\hline GWSC & -66.85 & 58.35 & -5.74 & 38.54 & - & - & - & - & - \\
\hline HMDSC & \begin{tabular}{|l|}
-73.29 \\
\end{tabular} & 87.45 & -3.27 & 45.71 & - & - & - & - & - \\
\hline TWSC & -42.24 & 57.34 & -3.18 & 29.96 & - & - & - & - & - \\
\hline $\mathrm{GW}$ & - & -1 & - & 28.24 & 0.03 & 0.00 & 7.06 & 24.49 & 27.94 \\
\hline TWSC vs. SMSC & - & - & - & 25.96 & 0.07 & 0.00 & 6.49 & 23.07 & 26.94 \\
\hline TWSC vs. GWSC & - & - & - & 9.83 & $\underline{0.91}$ & $\underline{0.83}$ & 2.46 & 9.57 & 10.20 \\
\hline TWSC vs. HMDSC & - & - & - & $\overline{15.92}$ & 0.82 & 0.67 & 3.98 & $\overline{13.35}$ & $\overline{17.25}$ \\
\hline
\end{tabular}

$S M S C=$ change in soil moisture storage; GWSC = change in groundwater storage;

$H M D S C=$ storage change in soil moisture and groundwater combined; TWSC = total water storage change; $S E M=$ standard error of the mean; $S E E=$ standard error of the estimate;

$S T D=$ standard deviation; $R M S E=$ root mean square error

the combined hydrological measurement data of soil moisture and groundwater. Groundwater storage is apparently high during the precipitation months of June to August. However, this is not always the case as saturated storage in the basin is also very much influenced by irrigation. Although irrigation is a form of internal water redistribution, its influence on the basin storage is very evident in the relatively minimal change in soil moisture storage on the one hand (bottom plate, Fig. 4), and the large aquifer head loss on the other (top plate, Fig. 3). Generally, however, soil moisture storage is influenced by several other factors including precipitation, irrigation, evapotranspiration, temperature, or even crop growth stage. Therefore its spatial and temporal dynamics and distribution are unusually complex. Irrespective of its complexity, minimal soil moisture storage change in the basin can largely be attributed to groundwater irrigation - the main drive of saturated storage loss in the basin (Figs. 4, 5 and 6). Furthermore, low temperatures in the cold and low-precipitation months of December to February limit evapotranspiration, thereby reducing soil moisture loss.

Table 1 details the statistical trends of the water storage components quantified in Eq. (1). At the monthly scale, soil moisture is insignificantly correlated with both total water storage $(\mathrm{R}=0.15$, $\mathrm{RMSE}=36.49 \mathrm{~mm})$ and groundwater storage $(\mathrm{R}=0.08$, RMSE $=35.84 \mathrm{~mm})$. This is because farmland irrigation (which augments soil moisture storage) is predominantly from groundwater storage, which is the primary source of total water storage change in the basin. Thus in the basin study area, soil moisture storage tends to be inversely related with the water balance components of groundwater and total water storage. Though generally weak, the GRACE-derived total water storage change has the strongest correlation with groundwater storage change $(\mathrm{R}=0.61$, $\mathrm{RMSE}=27.81 \mathrm{~mm})$. Irrespective of the weak correlations, the amplitudes (and more so the phases) of the water balance components have considerable similarities. This is particularly so for the GRACE-derived total water storage change and storage change obtained from the combined hydrological measurement data (Fig. 4). Storage is generally high for the high-precipitation months of June to August (summer season) and low for the low-precipitation months of December to February (winter season). For the basin study area, average annual storage depletion (in terms of equivalent water thickness) is $-12.72 \mathrm{~mm} / \mathrm{yr}$ for the GRACE data, -23.76 $\mathrm{mm} / \mathrm{yr}$ for the groundwater data, and $-13.44 \mathrm{~mm} / \mathrm{yr}$ for the combined hydrological measurements of soil moisture and groundwater. Based on the analysis, there is a storage increase of $10.32 \mathrm{~mm} / \mathrm{yr}$ in soil moisture. In contrast, however, there is a storage loss in groundwater. Taking the basin-averaged specific yield as 0.066 (Geological Memoirs, 1992), an equivalent of $360 \mathrm{~mm}$ thickness of saturated storage is depleted per year. If we further assume that all storage loss in the basin comes from saturated storage, then the GRACE-estimated storage loss is an equivalent of $192.93 \mathrm{~mm} / \mathrm{yr}$ of saturated storage thickness. By adjusting for the loss in saturated storage with the gain in rootzone soil moisture storage and again using the average specific yield of 0.066 , the GRACE estimate is commensurate with that of the combined hydrological measurement data (which is the equivalent of $203.64 \mathrm{~mm} / \mathrm{yr}$ of saturated storage thickness).

Despite the good similarities, however, some discrepancies exist at the monthly cycle. Hence the data were aggregated and compared at the seasonal scale. The results for the seasonal analysis are presented and discussed in the next sections.

\section{Seasonal storage change}

Averaging from lower to higher scale reduces data error as extrema and outliers are filtered out from the data (Wu et al., 2002). Hence at the seasonal cycle (Fig. 5, top plate), stronger correlations exist among the water balance components, except for soil moisture (see Table 1). For soil moisture, the lower correlation at the seasonal scale is due to its increasing inverse tendency with the other water balance components. Hence the SEE (standard error of the estimate) and RMSE are a better correlation measure for soil moisture at the seasonal scale (Table 1). In fact in the basin, saturated storage (but more so 


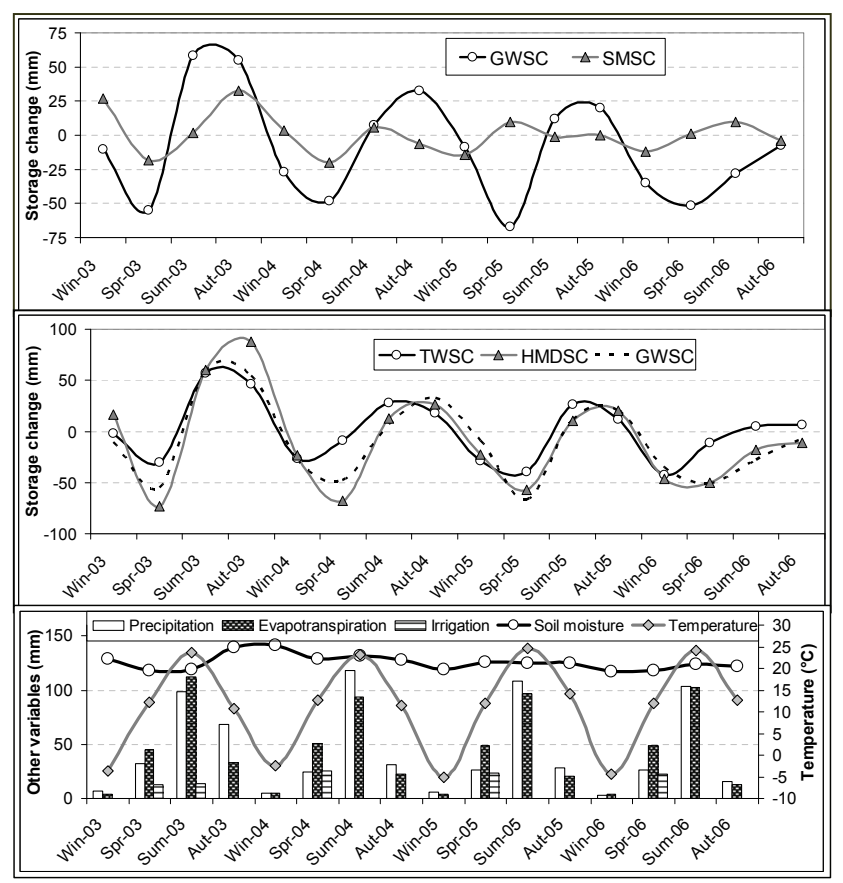

Figure 5

Time-series comparisons of the basin-averaged seasonal storage change in soil moisture and groundwater (top plate); and in the hydrological measurement (soil moisture and groundwater combined) and GRACE data (middle plate); along with seasonal trends of precipitation, irrigation, temperature, evapotranspiration and soil moisture (bottom plate) for the period 2003-2006. Acronyms are as defined in Table 1.

unsaturated storage) is influenced by both irrigation and precipitation (Yang et al., 2006; Han et al., 2008), which are in turn driven by temperature and evapotranspiration. Also because of the unusually thick unsaturated zone, groundwater recovery is mainly driven by lateral underflow from the neighbouring aquifer systems (Nakayama et al., 2006; Han et al., 2008). Although both the saturated and root-zone soil moisture storages are high in summer and low in winter, the amplitudes and phases are not so distinct for the root-zone soil moisture storage (Fig. 5 , top plate). Change in soil moisture storage is particularly moderated by groundwater irrigation in especially spring, low temperature and evapotranspiration in winter, and high precipitation in summer (see bottom plate, Fig. 5). It could therefore be stated that saturated storage is by far the most important source of storage change in the study area.

The middle plate in Fig. 5 is a comparison between the GRACE-derived total water storage change and storage change computed from the combined hydrological measurement data of soil moisture and groundwater. Over the seasonal cycle, the agreements are much stronger in amplitudes and phases (see Table 1 and Fig. 5). Generally, the highest and lowest amplitudes are in summer and spring respectively. The amplitudes are highest for 2003 (the year with the highest annual precipitation; $605.37 \mathrm{~mm}$ ) and lowest for 2006 (the year with the lowest annual precipitation; $446.62 \mathrm{~mm}$ ) for the period 2003 to 2006 . The stronger correlation (between the GRACE-derived total water storage and that from the hydrological measurement data) verifies that GRACE detects storage change in the basin study area. It also shows that storage change in the basin is sufficiently characterised by change in root-zone soil moisture storage and in groundwater storage.
Despite the good agreements, however, some discrepancies remain in the seasonal cycles. The discrepancies can be ascribed to a range of factors including differences in sensitivity and uncertainties in the hydrological data. For instance, while GRACE data are sensitive to virtually all sources of storage change, the hydrological measurement data are largely sensitive to changes in soil moisture storage and in groundwater storage. Differences in the time and frequency of sampling of the data sets constitute another source of discrepancy, e.g., whereas 3 soil moisture measurements are made per month, only 2 groundwater measurements are taken per month. Differences in spatial resolutions $\left(1^{\circ} \times 1^{\circ}\right.$ for the GRACE data, whereas they are not only sparse, but also uneven for the soil moisture and groundwater measurement data) are further reasons for the discrepancies. Instrumentation and processing errors (especially in the soil moisture measurement) induce additional limits on the agreements among the data sets (Swenson et al., 2006). Geographical truncation of GRACE data (Mayer-Guerr et al., 2007) and sparse groundbased measurements (Swenson et al., 2006) are other sources of discrepancy. But as these uncertainties are generally assumed to be uncorrelated (Wahr and Molenaar, 1998), they should have a negligible effect on the results of the spatial averaging. Furthermore, temporal analysis of the hydrological measurement data should stabilise this set of data and are therefore representative of the study area.

\section{Spatial trends of the water storage components}

Figure 6 depicts the annual averages (2003 to 2006) of the water storage components of precipitation, soil moisture, groundwater and GRACE-derived total water storage anomaly for the HRB study area. Precipitation, the most significant hydrological input in the basin, is highest in the south $(938.51$ $\mathrm{mm} / \mathrm{yr}$ ) and lowest in the north-west $(363.20 \mathrm{~mm} / \mathrm{yr})$. From the central floodplains down to the eastern coastal regions of Bohai Sea (where excessive groundwater irrigation occurs across the vast expanse of farmlands), precipitation is relatively moderate. The pattern of the hydrological input (mainly precipitation, but also the internal water redistribution of farm irrigation) and storage loss (mainly evapotranspiration), is more or less reflected in the overall storage pattern detected by GRACE. Based on GRACE data, the central plains are the worst storagedepletion zones in the basin. The storage pattern further suggests that GRACE responds more to regional storage change (also see Tapley et al., 2005; Swenson et al., 2006), hence GRACE data application in hydrological studies is for now limited to a minimum of $\approx 200000 \mathrm{~km}^{2}$ (Yeh et al., 2006).

For the soil moisture and groundwater storage, the plots on Fig. 6 shows a form of general relation between the 2 data sets (also see Table 1). While the water-table depth is highest in the central plain regions (indicating high saturated storage loss), soil moisture storage is highest for the same zones (indicating soil moisture augmentation mainly via groundwater irrigation). It then suggests that storage depletion in the basin and the larger Northern China is generally driven by farmland irrigation. In fact several other studies have identified agricultural irrigation as the principal driving factor of storage loss in the region (Brown et al., 2005; Kendy et al., 2006; Nakayama et al., 2006; Yang et al., 2006).

\section{Conclusion}

In this paper, total water storage change in Hai River basin was successfully estimated for the period January 2003 to 


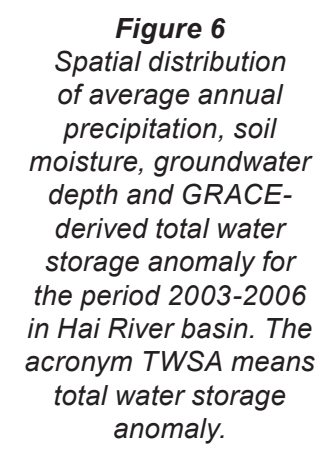

Figure 6
Spatial distribution of average annual precipitation, soil depth and GRACEderived total water storage anomaly for the period 2003-2006 in Hai River basin. The cronym TWSA means anomaly.
December 2006 using GRACE and in situ hydrological measurement data. Total water storage derived from GRACE data was compared with that computed from in situ hydrological measurement data of soil moisture and groundwater. There are good agreements between the GRACE and hydrological measurement data estimates of water storage change in the basin at especially the seasonal cycle. The favourable agreements imply that GRACE detects storage change in the $318866 \mathrm{~km}^{2} \mathrm{HRB}$ of Northern China. It also suggests that the hydrological measurement data of soil moisture and groundwater sufficiently characterise storage change in the basin study area.

Monthly and seasonal time-series of both the measured water-table depth and GRACE-derived water storage anomaly indicate storage loss in the basin. In the study area, storage loss is mainly driven by irrigation of the vast expanse of farmlands. Groundwater exploitation is therefore the main factor driving storage loss in the basin. Soil moisture storage change is the combined effect of precipitation, irrigation and evapotranspiration. As such, change in soil moisture storage is relatively minimal $(0.86 \mathrm{~mm} / \mathrm{month})$, compared with that in saturated storage (-1.98 mm/month; see Table 1). Therefore, efforts at water management and utilisation in the basin should focus largely on limiting evapotranspiration - the highest storage depleter in the study area (Kendy et al., 2004; Yang et al., 2002; Nakayama et al., 2006).

As storage depletion is an increasingly limiting factor to socio-economic development and crop production, GRACE data could be handy in monitoring not only the dynamics but also the availability of storage in the basin, the larger Northern China, and other regions with similar hydro-climatic conditions. Furthermore, hydrological models generally do not account for all basin storage components or are limited by elaborate input requirements and data pre-processing (Yeh et al., 2006). GRACE data could therefore provide a critical constraint on hydrological models for the accurate estimation of storage change and other hydrological processes in river basins or hydrologic regions.
It should, however, be noted that though GRACE takes into account virtually all sources of storage change, it performs relatively poorly at lower temporal and spatial scales (Tapley et al., 2005; Swenson et al., 2006). Furthermore, spatial smoothing of GRACE data for applications at smaller spatial scales induces a significant bias in GRACE estimates of mean monthly storage amplitudes (Klees et al., 2006). This makes bias corrections with a priori data almost inevitable in GRACE data applications. Despite the limitations, however, the potential of GRACE data in hydrological studies is huge. This is because unlike in situ hydrological measurements, GRACE data cover virtually every region of the world. Hence the combination of GRACE storage estimates with in situ hydrological measurement data allows not only the closing of basin/ regional water balance, but the verification and improvement of hydrological models. This could culminate into more accurate modelling of land and atmospheric hydrological processes.

\section{Acknowledgements}

This study was funded by Innovation Project No. KZCX1-YW08-03-04, International Collaborative Project of the Ministry of Science and Technology (2009DFA21690), and the Hundred Talent Program of Chinese Academy of Sciences. Hydrometeorological data were provided by the Hydrogeological and Meteorological Bureaus of Hebei Province. GRACE data were obtained from http://geoid.colorado.edu/grace/grace.php - which site is maintained by the University of Colorado at Texas, USA.

\section{References}

BLANKE A, ROZELLE S, LOHMAR B, WANG J and HUANG J (2007) Water saving technology and saving water in China. Agric. Water Manage. 87 139-150.

BROWN AE, ZHANG L, MCMAHON TA, WESTERN AW and VERTESSY RA (2005) A Review of paired catchment studies for determining changes in water yield resulting from alterations in vegetation. J. Hydrol. 310 28-61. 
BRUNNER P, FRANSSEN H-JH, KGOTLHANG L, BAUER-GOTTWEIN P and KINZELBACH W (2006) How can remote sensing contribute in groundwater modeling? Hydrogeol. J. 15 5-18.

CHAMBERS DP (2007) Evaluation of new GRACE time-variable gravity data over the ocean. Geophys. Res. Lett. 34 (14) 14402-1-14402-5.

CHEN Y, DEL-GENIO AD and CHEN J (2007) The tropical atmospheric El Niño signal in satellite precipitation data and a global climate model. J. Clim. 20 3580-3601. DOI:10.1175/JCLI4208.1.

FEI J (1998) Groundwater Resources in the North China Plain. Environ. Geol. \& Water Sci. 12 (1) 63-67.

FLAMSTEED S (2007) GRACE in Space: A Pair of Satellites Map Subtle Variations In Earth's Gravitational Field, Revealing Secret Craters, Undersea Mountains, and the Impact of Climate Change. Geodesy of the University of Texas at Austin Center for Space Research NASA/JPL. http://discovermagazine.com/2007/mar/ grace-in-space/article view?b start:int $=2 \&-C$.

GARCIA D, VIGO I, CHĀO BF and DEL-RIO J (2006) Interannual and annual variations in the Mediterranean Sea from satellite altimetry and GRACE data.

GEOLOGICAL MEMOIRS (1998) Comprehensive hydrogeologic evaluation of the Huang- Huai-Hai Plain. Ministry of Geology and Mineral Resources, People's Republic of China. Geological Publishing House, Beijing, Series 8 No. 11.

GUOBIN F, CHEN S, LIU C and SHEPARD D (2004) Hydro-climatic trends of the Yellow River basin for the last 50 years. Clim. Change 65 (12) 149-178.

HAN S, YANG Y, LEI Y, TANG C and MOIWO JP (2008) Seasonal groundwater storage anomaly and vadose zone soil moisture as indicators for precipitation recharge in the piedmont region of Taihang Mountain, North China Plain. Hydrol. Res. 39 (5-6) 479-495.

HINDERER J, ANDERSEN O, LEMOINE F, CROSSLEY D and BOY J-P (2006) Seasonal changes in the European gravity field from GRACE: A comparison with superconducting gravimeters and hydrology model predictions. J. Geod. 41 59-68.

KENDY E, ZHANG Y, LIU C, WANG J and STEENHUIS T (2004) Groundwater recharge from irrigated cropland in the North China Plain: case study of Luancheng County, Hebei Province, 19492000. Hydrol. Process 18 2289-2302.

KLEES R, ZAPREEVA EA, WINSEMIUS HC and SAVENIJE HHG (2006) The bias in RACE estimates of continental water storage variations. Hydrol. Earth Syst. Sci. Discuss. 3 3557-3594. www. hydrol-earth-syst-sci-discuss.net/3/3557/.

KUSCHE J, SCHMIDT R, PETROVIC S, and RIETBROEK R (2008) Decorrelated GRACE time-variable gravity solutions by GFZ, and their validation using a ydrological model. J. Geod. 1432-1394. DOI: 10.1007/s00190-009-0308-3.

MARTINEZ-FERNANDEZ J and CEBALLOS A (2003) Temporal stability of soil moisture in a large-field experiment in Spain. Soil Sci. Soc. Am. J. 67 1647-1656.

MAYER-GUERR T, ILK K-H, FEUCHTINGER M and EICKER A (2007) Global and Regional Gravity Field Solutions from GRACE Observations, CHAMP/GRACE Science Team Meet. 2004 Published online, www.gfzpotsdam.de/pb1/ JCG , 2005.

NAKAYAMA T, YANG Y, WATANABE M and ZHANG X (2006) Simulation of groundwater dynamics in the North China Plain by coupled hydrology and agricultural models. Hydrol. Process 20 3441-3466.

RIETBROEK R (2007) Validation of Oceanic Mass Changes derived from GRACE Gravimetry. A Comparison with Independent Data from Bottom Pressure Recorders in the Southern Ocean. Ph.D. thesis (unpublished), Delft University of Technology, Delft, The Netherlands.

RODELL M, CHEN J, KATO H, FAMIGLIETTI J, NIGRO J and WILSON C (2007) Estimating ground water storage changes in the Mississippi River basin (USA) using GRACE. Hydrogeol. J. 15 159-166. DOI: 10.1007/s10040-006-0103-7.

SENEVIRATNE S, VITERBO P, LÜTHI D and SCHAR C (2004) Inferring changes to terrestrial water storage using ERA-40 reanalysis data: the Mississippi River basin. J. Clim. 17 2039-2057.

SWENSON SC, YEH PJ-F, WAHR J and FAMIGLIETTI JS (2006) A comparison of Terrestrial water storage variations from GRACE with in situ measurements from Illinois. Geophys. Res. Lett. 33 L16401. DOI: 10.1029/2006GL026962.

SYED TH, FAMIGLIETTI JS, CHEN J, RODELL M, SENEVIRATNE SI, VITERBO P and WILSON CR (2005) Total basin discharge for the Amazon and Mississippi river basins from GRACE and a land-atmosphere water balance. Geophys. Res. Lett. 32 L24404. DOI: 10.1029/2005GL024851.

TONG S-J, LI J, YU Q and QIN Z (2009) Ecosystem water use efficiency in an irrigated cropland in the North China Plain. J. Hydrol. 374 (2009) 329-337. DOI: 10.1016/j.jhydrol.2009.06.030.

TAPLEY B, RIES J, BETTADPUR S, CHANBERS D, CHENG M, CONDI F, GUNTER B, KANG Z, NAGEL P, PASTOR R, PEKKER T, POOLE S and WANG F (2005) GGM02 - An improved Earth gravity field model from GRACE. J. Geod. 79 (8) 467-478.

WU B, JUN X, YAN N and YANG L (2008) ETWatch: An Operational ET Monitoring System with Remote Sensing. The ISPRS workshop on Geo-Information and Decision Support Systems, Iran.

WU W, GELLER MA and DICKINSON RE (2002) Time response of soil moisture to long-term variability of precipitation. $J$. Hydrometeorol. 3 604-613.

VACHAUD G, PASSERAT DE SILANS A, BALABANIS P and VAUCLIN M (1985) Temporal stability of spatially measured soil water probability density function. Soil Sci. Soc. Am. J. 49 822-828.

WAHR J and MOLENAAR M (1998) Time variability of the Earth's gravity field Hydrological and oceanic effects and their possible detection using GRACE. J. Geophys. Res. 103 (B12) 30,205-30,229.

XU Y and CAI Y (2005) GIS-based analysis on spatial-temporal change of groundwater level in the Hebei Plain. Acta Scientiarum Naturalium Universitatis Pekinensis 41 (2) 265-272.

YANG Y and TIAN F (2009) Abrupt change of runoff and its major driving factors in Haihe River Catchment, China. J. Hydrol. 374 373-383. DOI:10. 1016 /j.jhydrol.2009.06.040.

YANG Y, WATANABE M, TANG C, SAKURA Y and HAYASHI S (2002) Groundwater table and recharge changes in the piedmont region of Taihang Mountain in Gaocheng City and its relation to agricultural water use. Water SA 28 171-178.

YANG Y, WATANABE M, ZHANG X, ZHANG J, WANG Q and HAYASHI S (2006) Optimizing irrigation management for wheat to reduce groundwater depletion in the piedmont region of the Taihang Mountains in the North China Plain. Agric. Water Manage. 82 25-44.

YEH PJ-F, SWENSON SC, FAMIGLIETTI JS and RODELL M (2006) Remote sensing of groundwater storage changes in Illinois using the Gravity Recovery and Climate Experiment (GRACE). Water Resour. Res. 42 W12203. DOI: 10.1029/2006WR005374. 